\title{
Perspective
}

PERSPECTIVE Actualité en histoire de l'art

Comptes rendus | 2010

\section{Sabine Frommel, Flaminia Bardati éd., La réception de modèles cinquecenteschi dans la théorie et les arts français du XVII siècle, Genève, Droz, 2010}

\section{Stéphane Loire}

\section{OpenEdition \\ Journals}

Édition électronique

URL : http://journals.openedition.org/perspective/2562

DOI : $10.4000 /$ perspective. 2562

ISSN : 2269-7721

Éditeur

Institut national d'histoire de l'art

Référence électronique

Stéphane Loire, « Sabine Frommel, Flaminia Bardati éd., La réception de modèles cinquecenteschi dans la théorie et les arts français du xvII siècle, Genève, Droz, 2010 », Perspective [En ligne], Comptes rendus, mis en ligne le 01 août 2013, consulté le 01 octobre 2020. URL : http://journals.openedition.org/ perspective/2562 ; DOI : https://doi.org/10.4000/perspective.2562

Ce document a été généré automatiquement le 1 octobre 2020. 


\section{Sabine Frommel, Flaminia Bardati} éd., La réception de modèles cinquecenteschi dans la théorie et les arts français du XVII siècle, Genève, Droz, 2010

Stéphane Loire

\section{RÉFÉRENCE}

Sabine Frommel, Flaminia Bardati éd., La réception de modèles cinquecenteschi dans la théorie et les arts français du XVII e siècle, Genève, Droz, 2010. 
1 Issues d'un colloque qui s'est tenu en 2006, les dix-sept contributions réunies dans ce volume examinent divers exemples d'emprunts et d'appropriations par les artistes et les théoriciens français $\mathrm{du} \mathrm{XVII}^{\mathrm{e}}$ siècle de modèles nés en Italie au siècle précédent. Certains se rapportent à des épisodes déjà bien connus - l'édification $d u$ palais $d u$ Luxembourg à Paris sur le modèle du palais Pitti de Florence, le voyage à Paris de Nicolas Poussin en 1640, le concours pour la façade orientale du Louvre - mais tous sont examinés ici avec la volonté de mettre en évidence les effets de la migration des artistes, de leurs créations et de leurs langages. Prenant la forme de voyages, de transferts de textes et de modèles graphiques, ou tout simplement de déplacements d'œuvres bien identifiables, ces mouvements sont évoqués à travers des études de cas complémentaires qui devraient favoriser une compréhension plus fine de la pensée et de la production artistique du Grand Siècle. Ainsi, l'accent est mis sur le rôle de précurseur de Roland de Fréart de Chambray pour la formulation d'un discours théorique national, sur la réception discrète des modèles transalpins par des sculpteurs français $\mathrm{du} \mathrm{XVII}{ }^{\mathrm{e}}$ siècle, ou encore sur l'assimilation critique des traités italiens dans le Cours d'architecture (1675) de François Blondel. C'est d'ailleurs pour l'architecture, s'agissant de monuments réalisés ou simplement de projets, que l'examen des relations avec le Cinquecento s'avère le plus stimulant: qu'il s'agisse de la multiplication des églises à coupoles dans le paysage urbain parisien, de la réception des modèles graphiques de Vignole ou de l'adaptation du chapiteau ionique de Scamozzi, l'art de bâtir paraît bien avoir été un domaine privilégié pour l'assimilation et le dépassement des modèles italiens. 